\title{
QUALIDADE E RELEVÂNCIA DO LAUDO DA PERÍCIA CONTÁBIL JUDICIAL: UM ESTUDO DE CASO À LUZ DA TEORIA DAS EXPECTATIVAS
}

\author{
Cintia Assagra Escalfi ${ }^{1}$ \\ Giulia de Oliveira Romão ${ }^{2}$ \\ Edileusa Cristina Borçato ${ }^{3}$
}

ESCALFI, C. A.; ROMÃO, G. de O.; BORÇATO, E. C. Qualidade e relevância do laudo da perícia contábil judicial: Um estudo de caso à luz da teoria das expectativas. Rev. Ciênc. Empres. UNIPAR, Umuarama, v. 19, n. 1, p. 141-160, jan./jun. 2018.

RESUMO: É notável a precisão da perícia contábil como suporte para auxiliar os magistrados em suas tomadas de decisões em assuntos relacionados a patrimônio e finanças patrimoniais. Desta forma, o laudo se torna importante àquele que precisa de ajuda e instruções técnicas para julgar, logo é imprescindível que o laudo pericial contábil seja qualificado para que seja utilizado como prova. Todavia, torna-se significativa esta pesquisa da qual o objetivo geral foi examinar a qualidade e relevância dos laudos periciais contábeis para os magistrados das varas cíveis de Umuarama e região. Este estudo é exploratório-descritivo, transversal, com abordagem qualitativa, cuja coleta de dados ocorreram durante três meses, sendo de setembro a novembro de 2017, em 17 municípios, em uma amostra de oito juízes, sendo que apenas quatro juízes responderam à pesquisa pessoalmente e um respondeu via internet através do questionário eletrônico estruturado pelo software Survio. O desfecho da pesquisa informa que os magistrados esperam que o perito contador tenha características referentes à índole de um profissional contábil, jamais esquecer da ética e da educação continuada, sempre ter competência para elaborar o laudo. Assim, fica evidente a satisfação do laudo pericial para os magistrados das comarcas das varas cíveis de Umuarama e região.

PALAVRAS-CHAVE: Perícia. Perito. Laudo Pericial.

DOI: $10.25110 /$ receu.v19i1.6719

${ }^{1}$ Graduanda em Ciências Contábeis pela Universidade Paranaense, UNIPAR, unidade universitária de Umuarama - cintiaescalfi_16@hotmail.com

${ }^{2}$ Graduanda em Ciências Contábeis pela Universidade Paranaense, UNIPAR, unidade universitária de Umuarama - giuliaromao@hotmail.com

${ }^{3}$ Mestra em Contabilidade, Docente na UNIPAR, unidade universitária de Umuarama - prof. edileusaborcato@gmail.com 


\title{
QUALITY AND RELEVANCE OF THE JUDICIAL FINANCIAL AUDIT: A CASE STUDY ACCORDING TO THE EXPECTATION THEORY
}

\begin{abstract}
The accuracy of a financial audit to support judges in their decisionmaking processes in matters related to assets and equity finances is undeniable. Therefore, an audit report becomes important for those who require help and technical instructions in order to make judgements, and thus, it is essential that the financial audit report is qualified in order to be used as evidence. This study aims at examining the quality and relevance of financial audit reports for the magistrates at the civil courts in the city of Umuarama and its region. It is an exploratory-descriptive cross-sectional study with a qualitative approach, with data collected over a three-month period, ranging from September to November 2017, in 17 cities, in a sample consisting of eight magistrates, considering that only four of them replied to the survey in person and one answered it via the Internet through an electronic questionnaire structured using the software Survio. The findings inform that the magistrates expect the accounting expert to present characteristics related to the nature of an accountant, never forgetting the ethics and continuous education aspects, and having the competence to prepare the report. Thus, those characteristics are sufficient to provide financial audit reports to the magistrates at the civil courts in the judicial districts of Umuarama and its region.
\end{abstract}

KEYWORDS: Expert; Expertise; Forensic report.

\section{CALIDAD Y RELEVANCIA DEL LAUDO DE LA PERICIA CONTABLE JUDICIAL: UN ESTUDIO DE CASO A LA LUZ DE LA TEORÍA DE EXPECTATIVAS}

RESUMEN: Es notable la precisión de la pericia contable como soporte para auxiliar a los magistrados en sus tomas de decisiones en asuntos relacionados al patrimonio y finanzas patrimoniales. De esa forma, el laudo se hace importante al que necesita ayuda e instrucciones técnicas para juzgar, luego es imprescindible que el laudo pericial contable sea calificado para que sea utilizado como prueba. Sin embargo, se hizo significativa esta investigación pues, el objetivo general ha sido examinar la calidad y relevancia de los laudos periciales contables para los magistrados de las varas civiles de Umuarama y región. Este estudio es exploratorio y descriptivo, transversal, con abordaje cualitativo, cuya recolección de datos ocurrió durante tres meses, siendo de septiembre a noviembre de 2017, en 17 municipios, en una muestra de ocho jueces, siendo que sólo cuatro jueces respondieron a la encuesta personalmente y uno contestó vía internet a través del cuestionario electrónico estructurado por software Survio. El resultado de 
la encuesta informa que los magistrados esperan que el experto contador tenga características referentes a la índole de un profesional contable, jamás olvidarse de los aspectos éticos y de la educación continuada, siempre tener competencia para elaborar el laudo. Así, queda evidente la satisfacción del laudo pericial para los magistrados de las comarcas y de las varas civiles de Umuarama y región.

PALABRAS CLAVE: Laudo Pericial; Pericia; Experto.

\section{INTRODUÇÃO}

Possuem evidências que a perícia já havia desde o início da humanidade, contribuindo assim com o crescimento da racionalidade humana, trazendo consigo o poder da superioridade. Essa soberania exercia o papel de autoridade que comandava a sociedade, pois elaboravam, julgavam e examinavam leis. Claramente que ainda não se classificava como perícia, mas a razão da examinação dos atos e fatos, coisa ou situação já estampava o tipo da ciência, assim dizia Alberto (2002).

Segundo Sá (2002) até o século XVIII existiam Técnicas Contábeis que derivam de atividades realizadas por profissionais contábeis há um milênio, pois ainda não havia teorias e bases científicas. Com a aplicação das técnicas de verificação dos eventos, a contabilidade desenvolveu várias especializações, dentre elas a Perícia.

No Brasil, a perícia destacou-se em meados de 1939, com a instituição do Código de Processo Civil. Segundo Magalhães, Souza e Favero (2004), a Perícia Contábil surgiu como área profissional devido ao Decreto-Lei no 9.295/46, propiciando ao país o Conselho Federal de Contabilidade.

Com a melhoria da performance do profissional e seu reconhecimento com o magistrado, o Conselho Federal de Contabilidade (CFC) criou e divulgou a Norma Brasileira de Contabilidade (NBC) Técnica Profissional (TP) 01, definindo a Perícia em um conjunto de metodologia técnica e científica que leva à jurisdição elemento de prova significativa à solução de pendências por intermédio do laudo pericial contábil e/ou parecer pericial contábil (CFC, 2009a).

Os laudos demonstrarão os resultados dos procedimentos realizados pelos peritos, sendo assim mensurar a qualificação desses procedimentos resultará benefícios para os interessados no assunto e profissionais da área. Neves Junior, Moreira e Ribeiro (2013) dizem que o laudo declara como um mecanismo significativo e inevitável para a tomada de decisão do juiz, ressaltando também que a importância e a satisfação do laudo vêm devido à qualidade da execução dos procedimentos e realização do trabalho dos peritos-contadores.

Da mesma forma, Sá (2002) afirma que quase sempre o valor do laudo é reflexo da habilidade de quem o elaborou. Portanto, é imprescindível que o 
perito tenha conhecimento científico sobre o objeto periciado e os procedimentos adequados e eficientes para tornar o laudo relevante.

Contudo, é importante averiguar a opinião daqueles que utilizam as informações contidas nos laudos para compreender se estas possuem a qualidade esperada e se são relevantes para auxiliar no processo de sentença do magistrado.

Apesar de conter antigos registros de experiências periciais, esta especialização se encontra em processo de desenvolvimento e ciente da escassez de estudos, especificamente voltados ao conhecimento científico sobre laudos periciais, torna-se relevante este estudo que tem como sujeitos de pesquisa os juízes das varas cíveis e juízo único das comarcas de Umuarama e região e terá como base a pesquisa de Leitão Junior, Slomski, Mendonça e Peleias (2012) que realizaram estudo similar na cidade de São Paulo. O diferencial da reaplicação deste estudo está na ótica das análises que terá como base a Teoria das Expectativas.

Logo, a questão de pesquisa que norteará este estudo se apresenta da seguinte forma: Qual a expectativa e a percepção dos juízes titulares das varas cíveis e do juízo único das comarcas de Umuarama e região em relação à qualidade e relevância do laudo pericial contábil? Desta maneira tem-se como objetivo geral conhecer a expectativa e a percepção dos juízes em relação à qualidade e relevância do laudo pericial para os magistrados titulares das varas cíveis e de juízo único das comarcas do noroeste do estado do Paraná.

Para responder à questão de pesquisa apresentam-se os seguintes objetivos específicos: conhecer o perfil dos juízes; identificar o perfil e as características ideais dos peritos contadores judiciais; identificar quando se faz necessário nomear um perito; formas de escolha de peritos pelos juízes; conhecer as deficiências dos laudos periciais; identificar quando os laudos são utilizados como base para as decisões judiciais; constatar se os laudos atendem às expectativas dos juízes.

Este artigo está organizado em cinco capítulos. O primeiro capítulo compõe-se a esta introdução que apresenta uma breve contextualização de perícia, o problema, a justificativa, a questão de pesquisa e os objetivos gerais e específicos. O segundo capítulo destina-se a fundamentação teórica que conceitua a perícia, o perito e o laudo pericial contábil. O capítulo três expõe a metodologia adotada neste estudo e como quarto capítulo tem-se a apresentação e análise dos dados e por fim, as referências.

\section{METODOLOGIA}

A construção da pesquisa se iniciou com a sua classificação em concordância com o objetivo, procedimento, abordagem do problema, população, tipos de amostragem e instrumento. Sucessivamente, houve a elaboração do questio- 
nário e o envio aos juízes para que respondessem e assim fosse feito o levantamento das informações e ter consciência da importância e relevância do laudo pericial contábil.

O artigo em questão tem os estudos exploratório-descritivos combinados como objetivo, conceituado por Marconi e Lakatos (2009) que os estudos exploratórios descrevem determinado fenômeno completamente, fornecendo maiores esclarecimentos sobre o assunto em indagação.

Oliveira (1998) expõe que as pesquisas descritivas têm por propósito expor a característica de um grupo definido a fim de informar qual a opinião da população sobre quesito, capaz de gerar uma nova visão do problema em questão.

O procedimento foi realizado por levantamento, onde recorreu a fontes primárias para colher informações. As informações foram auferidas por meio do questionário eletrônico respondido pelos juízes das varas cíveis e juízo único das comarcas de Umuarama e região, cidade do Noroeste do Paraná.

Quanto à abordagem do problema, a pesquisa é qualitativa, desempenhada em cenários naturais e notada sobre dois fatores: comportamentais e fatos, assim dito por Creswell (2007).

A pesquisa foi efetuada no município de Umuarama e região (Figura 1), totalizando 17 municípios em pesquisa. Contudo, somente em 6 municípios há comarcas, sendo que 2 destes há varas cíveis e 4 dependem do juízo único, totalizando 8 juízes em toda a comarca regional.

Figura 1: Mapa do noroeste do Paraná

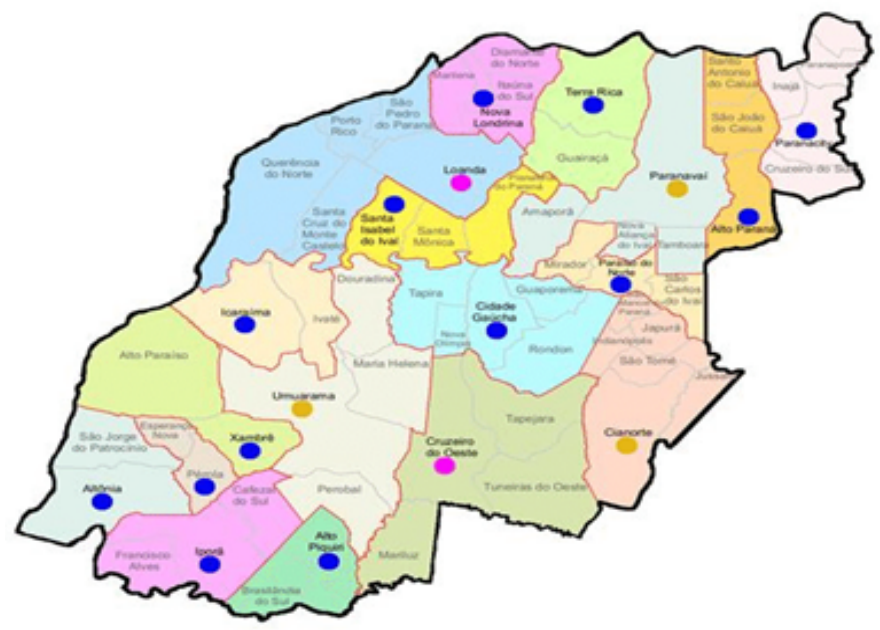

Fonte: Researchgate (2017) 
Foram encaminhados 8 questionários conforme a quantidade de jurisdição de Umuarama e região e 5 responderam, desta forma apontando que houve retorno de $62,5 \%$.

A perspectiva temporal da pesquisa é transversal, porque a coleta de dados ocorreu no mês de setembro a novembro de 2017. Para Richardson (1999), a coleta de dados acontece com base em uma amostra escolhida e que descreve a população naquele determinado período, consequentemente, não havendo comparação entre períodos.

O mecanismo utilizado para coletar os dados foi o questionário online pelo software Survio, estruturado com 12 perguntas a fim de obter de fontes primárias o perfil dos juízes e a satisfação para com o laudo pericial contábil. Os instrumentos foram validados e efetuados pré-teste com mestrandos de contabilidade de uma universidade pública estadual do Estado do Paraná. Os resultados foram tabulados em planilha dos softwares Excel v.2013 e Word v.2013.

\section{FUNDAMENTAÇÃO TEÓRICA}

Neste capítulo apresenta-se a conceituação dos perfis dos juízes e dos peritos, a conceituação e a normatização da perícia contábil, a descrição de quais qualidades e exigências que o perito contador deve ter, caracteriza a ferramenta principal utilizado pelo perito contábil, demonstra análises semelhantes a este artigo e por fim, conceitua a Teoria da Expectativa.

\subsection{Perfil dos Juízes}

O juiz precisa ter um perfil em concordância com o Conselho de Ética da Magistratura Nacional (CEMN) para que tenha moralidade perante a sociedade e assegurar a legitimidade do Poder Judiciário. As principais características retratadas no CEMN aconselham os juízes a serem imparciais diante das partes ao buscar as verdades dos fatos, ser transparente, informar aos interessados a desenvoltura e progressão do processo, manter sigilo das informações obtidas pelo seu serviço, ter integridade pessoal e profissional para que suas ações tenham credibilidade ante o Poder Judiciário.

Para Passo (2013), as atividades dos juízes não se limitam às atividades-fim e atividade-jurisdicional, mas à atividade-meio, referente à atividade de natureza administrativa que oferece meios necessários para oportunizar a realização do direito, em razão da qual os magistrados comportam-se na sua unidade administrativa. Desse modo, os encargos de natureza administrativa exigem ao perfil do juiz capacidades de se atualizar nas demandas sociais e funções de prever, organizar, orientar e coordenar uma atividade organizacional. 


\subsection{A Perícia Contábil e o perfil do Perito Contador}

Para Hoog e Petrenco (2003), a perícia originou-se do termo em latim peritia, na qual significa "conhecimento", onde este conhecimento quando colocado à disposição, será o intermediário para a obtenção de determinada prova.

A Perícia Contábil fraciona como arbitral, estatual, voluntária e judicial. A perícia arbitral é gerenciada pela Lei de arbitragem; a estatual sob controle do Estado; a voluntária quando é contratada espontaneamente; e a judicial, utilizada neste artigo, é exercida como auxiliar da Justiça, conceituadas conforme CFC (2009a).

Para Alberto Filho (2011), o perito contador é todo homem que tiver a comprovação da habilitação técnica especializada, com autorização comprovada do conhecimento do objeto, ou seja, é a pessoa bacharelada em Ciências Contábeis que se tornou especialista em determinado assunto. Logo, o perito contador judicial será o especialista no processo em que for solicitado pelo poder Judiciário.

Em conformidade com o Código de Ética Profissional do Contador (CEPC), no capítulo II, o Profissional de Contabilidade tem o compromisso de exercer a profissão com zelo, honestidade, diligência e capacidade técnica (CFC, 1996), livrando seu trabalho dos interesses particulares dos clientes, sem calamidade ou injustiça com as partes.

A norma responsável pela operação do contador como perito é a NBC PP 01 (CFC, 2009b) que enfatiza o zelo, a responsabilidade e a habilitação profissional como atributos necessários em um profissional, enquanto a NBC PG 100 (CFC, 2014), é responsável pela Aplicação Geral aos Profissionais de Contabilidade, complementa ao perfil do contador conceitos éticos, como integridade, objetividade, competência profissional, sigilo e comportamento.

Segundo Gonçalves, Machado, Machado e Zanolla (2014), o "zelo" diz respeito à cautela com que o profissional deve observar e produzir a perícia em relação à sua conduta, prazos, documentos, entre outros fatores, pois tudo o que for apresentado no laudo pericial contábil ou parecer técnico-contábil será de responsabilidade do perito.

É necessário que o perito tenha comprometimento e que respeite os princípios éticos, morais e de direito, atuando com boa-fé. "Como exemplo de responsabilidade, cita-se o fiel cumprimento dos prazos estabelecidos pelo juízo", falado por Carvalho e Marques (2005, p. 41). Caso contrário, arcará sob penalidade criminal, ética, profissional e civil pela sua conduta, assim dito por Hoog e Petrenco (2003).

Em relação à habilitação legal, Gonçalves, Machado, Machado e Zanolla (2014) descrevem que a técnica legal é atribuída àquele bacharelado em Ciências Contábeis e com registro no conselho regional de contabilidade. É ne- 
cessário que comprove a habilidade profissional no primeiro ato de perícia, anexando na apresentação do laudo ou parecer.

Também cabe ao perfil do perito a aprovação na prova de Qualificação Técnica, conforme a NBC PP 02 (CFC, 2016), que entrou em vigor em $1^{\circ}$ de janeiro de 2017, na qual relata sobre a qualificação técnica para o perito contador, para conferir os conhecimentos e a competência do profissional que atua na área.

Muller, Antonik e Ferreira Junior (2008) defendem que a perspicácia é uma qualidade indispensável em um perito, pois está relacionada com a concentração e a capacidade de observação para identificar o objeto da perícia e assim aprimorar o laudo pericial.

Pires (1999) expôs que o profissional que atua como perito contador deve conter conhecimentos gerais de todas as ciências que estão relacionadas com a contabilidade. Com isso, torna-se necessário que o perito tenha continuação em seus estudos em busca constante do aprimoramento técnico-científico.

\subsection{Nomeação do Perito Contador e Perito Contador Assistente}

A escolha do Perito Contador ocorre pela necessidade de informação técnica e científica do magistrado decorrente ao caso e objeto que precisa ser examinado, vistoriado ou avaliado. A escolha é feita a partir do cadastro mantido pelo tribunal ao qual o juiz está vinculado, onde devem estar legalmente habilitados, comprovando a habilidade profissional como pedido na Lei 13105 (BRASIL, 2015).

Há também a possibilidade de contratação de um perito assistente, pelas partes, constado no art. 466 da mesma lei. O perito contador assistente acompanhará os trabalhos do perito, se for aceito por este, e sucessivamente dará seu parecer pericial em conformidade com o prazo constituído, exceto na ocasião em que o laudo é conjunto, onde o assistente assinará o laudo com o perito-contador.

Após estar ciente da sua nomeação no caso, o perito contador tem 15 (quinze) dias para enviar ao magistrado seu currículo e comprovante de habilitação, sua proposta de honorário e contatos profissionais. Assim, terá retorno da arbitragem do valor feita pelo juiz após 5 (cinco) dias, conforme a Lei 13105/15, art. 465.

Segundo o art. 467 da mesma lei, estabelece que o perito pode dispensar-se ou ser negado por impedimento ou suspensão, tendo a nomeação de outro perito para o caso. A substituição do perito acontecerá pela falta de entendimento técnico ou científico do objeto e até por descumprimento de algo que o juízo requisitou, como não entregar a documentação em um estipulado prazo.

\subsection{Laudo Pericial}

Cruz, Xavier, Santos, Carmo e Teixeira (2016) relatam que a principal 
função da prova pericial é converter fatos em verdade formal, em veracidade à jurisdição, ou seja, materializar a prova em laudo pericial.

O Laudo Pericial Contábil é definido como um documento composto pelo profissional contábil (perito), evidenciando posteriormente o resultado do seu serviço. A norma exige que o perito-contador conclua o Laudo Pericial Contábil de maneira precisa e clara (CFC, 2009a). Essa parte é essencial para atestar a opinião técnica do perito contábil sobre os segmentos definidos nos requisitos.

Para a elaboração do laudo é preciso identificar as dúvidas pela qual o juiz solicitou o perito, para que assim o contador responda com precisão o questionamento que sucessivamente servirá como prova.

Santana (1999) relata que a estrutura e a organização das informações descritas no laudo pericial determinarão a utilidade e o proveito com êxito. Contudo, a NBC TP 01 (CFC, 2009a) estipulou que o Laudo Pericial Contábil deve conter, no mínimo, os seguintes itens: identificação dos processos e das partes; síntese do objeto da perícia; critério utilizado para os trabalhos periciais; identificação de como as provas foram coletadas; transcrição e resposta aos quesitos; conclusão; anexos; apêndices; e assinatura do Perito-Contador.

Cruz et al. (2016) consideram que o profissional deve expor sua fundamentação de forma que tenha uma linguagem simples e com coerência lógica àqueles que utilizam das informações. Em razão disso, o perito precisa ter uma boa comunicação escrita para conseguir exibir todo o seu domínio e conhecimento.

Os laudos devem atrair os leitores por meio de sua apresentação, pois é a exposição do trabalho do perito e o mesmo deve valorizá-lo (ORNELAS, 2003). Sendo assim, os laudos se dividem em quatro tipos: Laudo Pericial que é a prova fornecida pelos peritos, com finalidade de proporcionar esclarecimentos à lide; Relatório de vistoria que é o laudo vistoriado em determinado tempo, objeto e lugar; Laudo de Louvação que é a análise de bens, débitos e coisas, na qual depende do conhecimento de outro especialista sobre área definida; e Parecer Pericial que é o documento expresso pelo perito-assistente, mostrando objetividade e clareza sobre o resultado obtido.

\subsection{Estudos anteriores}

O estudo de Medeiros e Neves Junior (2006) informou a visão dos magistrados das cidades do Rio de Janeiro e Brasília referente ao trabalho dos peritos-contadores. Assim, foi demonstrado que 70\% dos juízes entrevistados seguiram as indicações dos laudos. Na mesma pesquisa apresentaram-se necessidades de melhorias técnicas da parte dos juízes.

Neves Junior e Rivas (2007) pesquisaram sobre a qualidade dos Laudos Periciais e sua influência na tomada de decisão dos magistrados das Comarcas de 
Fortaleza e do Distrito Federal. Constataram que as atividades periciais influenciam nas escolhas praticadas pelos juízes e em relação à qualidade dos laudos apuraram que os peritos são sensatos e satisfazem a maior parte do parecer, pecando na maneira de constatar e nos requisitos.

Bleil e Santin (2008) estudaram a percepção dos julgadores no estado do Rio Grande do Sul, especificamente na cidade de Erechim em relação à qualidade e competência dos laudos exibidos aos juízes. O resultado da pesquisa demonstrou que $72 \%$ dos que usufruíram os laudos opinam que as ferramentas dadas pelos peritos são de qualidade, porém, também informou que os trabalhos devem ser descritos em linguagem mais clara e explícita, em razão de não ser direcionados aos profissionais de contabilidade, mas sim a quem desconhece os meios técnicos da contabilidade.

$\mathrm{Na}$ averiguação feita por Zochio (2010) no estado de São Paulo sobre a importância dos laudos periciais nas resoluções dos processos judiciais, expôs que apesar de sua relevância da prova pericial, seu desenvolvimento pode ser aperfeiçoado, de modo que os profissionais contábeis necessitam de mais habilidades e preparos.

Zolet e Silvério (2009) pesquisaram nas comarcas dos municípios do sudoeste do Paraná sobre a influência da ferramenta nas decisões dos magistrados. Expôs então, que os laudos foram aprovados e também apontaram necessidades de haver melhoria na linguagem escrita utilizada pelos peritos-contadores.

\subsection{Teoria das expectativas}

A teoria da expectativa é uma tentativa de atingir um modelo, demonstrar como os humanos optaram racionalmente a se motivar ou não por um evento particular de ação. "A "teoria da expectativa" de Victor H. Vroom provê um modelo de quando as pessoas decidem exercer autocontrole para perseguir um determinado objetivo" (VROOM, 1964 apud HINTEMANN, 2006, p. 10). Assim, as expectativas de todos em relação ao trabalho é a combinação entre as forças de seus propósitos e dos objetivos, produzindo um apoio motivacional.

A justificativa dessa teoria é que o entendimento das metas pessoais ou profissionais de um indivíduo é a fusão entre a dedicação e a execução, cumprimento e realização, e finalmente entre a recompensa e a satisfação individual ao alcançar a meta.

A base dessa teoria é o comportamento e a estrutura psicológica do ser humanos e os autores Borges e Alves Filho (2001) atestam a teoria de Victor Vroom que se consagrava no meio da motivação, em que aplicavam o livro "Psicologia Organizacional e Trabalho", do autor Georgopoulas, Mahoney e Jones, que assume a conexão entre o esforço realizado e o rendimento do trabalho.

Para Robbins (2002) a Teoria de Victor H. Vroom resulta o proveito 
do indivíduo em combinações entre escolhas humanas, como vontades e expectativas que todos possuem, porém, de forma diferente. Com isso, a motivação submete-se aos fatores, tais como: valência, expectância e instrumentalidade.

A valência pode acontecer na ligação entre a meta cumprida e os graus de sua relevância; a expectância condiz ao que o indivíduo pretende ser capaz de realizar seu objetivo e; a instrumentalidade é o entendimento de que o trabalho efetuado levará o indivíduo a atingir a meta esperada.

Contudo, a motivação (M), a expectância (E), a instrumentalidade (I) e a valência $(\mathrm{V})$ estão listadas entre si pela fórmula: Motivação $=$ Expectância $\mathrm{x}$ Instrumentalidade x Valência $(\mathrm{M}=\mathrm{E} \times \mathrm{I}$ x V).

Ainda para Robbins (2002), a Teoria da Expectativa é aplicável no ambiente de trabalho, notado que elementos da fórmula são encontrados e consistentes com a atividade profissional. Todos possuem forças motivacionais, porém com diversas situações, reações e finalidade, como por exemplo: um trabalhador que não está satisfeito com o valor do pagamento. A insatisfação interferirá o modo de produção e até seu comportamento emocional, pois já não é mais prazeroso dar o seu máximo para tal atividade.

Quando se trata da aplicação dessa Teoria no ramo da perícia, o perito estará motivado quando ocorrer a nomeação para o caso, pois assim o perito aplicará o conhecimento que tanto adquiriu sobre determinado objeto. A experiência do caso também é uma motivação para o contador, assim como a remuneração. O perito estará satisfeito quando conseguir aplicar seus conhecimentos e ajudar o juízo a tomar decisão.

\section{APRESENTAÇÃO E ANÁLISE DOS DADOS}

Após a pesquisa de campo ser realizada, ocorreu a tabulação dos dados a fim de revelar com gráficos ilustrativos as opiniões dos magistrados. Em princípio, perguntou-se o gênero e a idade dos mesmos. Resultando que a pesquisa apontou que $60 \%$ são masculinos e $40 \%$ femininos.

Em relação à idade, constatou-se que $20 \%$ dos magistrados têm de 25 a 35 anos, enquanto $80 \%$ possuem de 35 a 45 anos.

Se tratando ainda do perfil dos magistrados, $20 \%$ deles também têm graduação em Ciências Contábeis.

Constatou-se também que os juízes atuam na área há bastante tempo. Com escolha entre 3 a 5 anos, 5 a 10 anos e acima de 10 anos, o fecho foi de $20 \%$, $20 \%$ e $60 \%$, sucessivamente.

Em relação à ética e o comportamento profissional, $80 \%$ dos juízes pronunciaram que sempre desejam ética e comportamento profissional no caso, enquanto $20 \%$ relatam que geralmente são necessárias ambas características. A 
objetividade no processo sempre foi desejada por $60 \%$ dos juízes e a sobra admite que geralmente é esperado que o perito tenha posicionamento coerente perante o procedimento, conforme apresentado no Gráfico 1.

Quando o assunto é sigilo, as respostas sempre e geralmente obtiveram uma similaridade de $40 \%$ e $20 \%$, às vezes, desejam tal característica para o profissional do caso. O mesmo acontece com o conhecimento multidisciplinar, expondo que a maioria dos magistrados prefere que os peritos entendam de outras áreas científicas, constado no figura 2.

Por almejar conhecimento, o quesito de formação continuada, $80 \%$ dos magistrados desejam que os peritos invistam na sua qualificação intelectual e $20 \%$ geralmente esperam isso, conforme figura 2 . A mesma proporção foi dada ao zelo, indicando que a maioria dos magistrados esperam que os peritos tenham cuidado com os documentos e prazos.

A habilitação profissional alcançou porcentagens de $60 \%$ e $40 \%$ para sempre e geralmente, sucessivamente, constatando que é essencial que o profissional contábil tenha habilitação no CRC - Conselho Regional de Contabilidade, assim como também tenha destreza para executar sua função.

A imparcialidade usufrui da mesma proporção, demonstrando que os magistrados esperam que os peritos tenham imparcialidade nos laudos para que nenhuma parte interfira no resultado. Diferente de todos, o requisito da perspicácia resultou em $80 \%$ para geralmente e $20 \%$ para sempre, conforme figura 2 .

Figura 2: Perfil ético e comportamento profissional dos peritos conforme desejo dos juízes

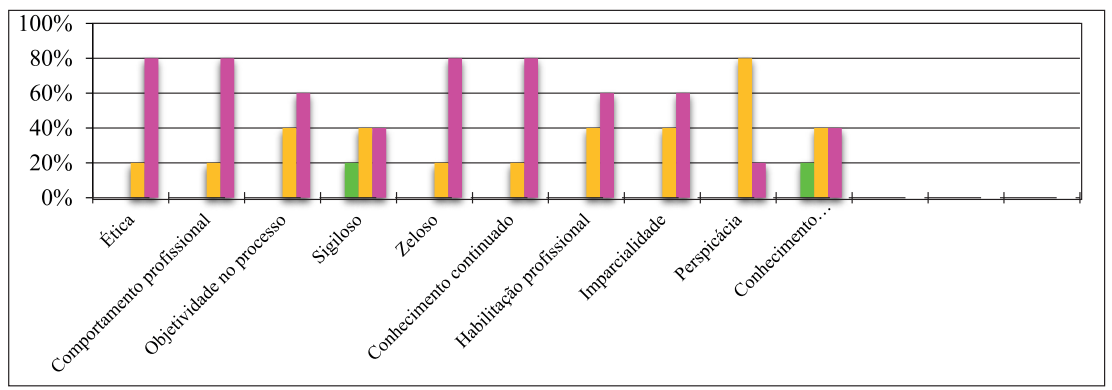

Fonte: Elaborado pelas autoras, 2017.

Por meio do questionamento pode-se concluir que a nomeação do perito acontece quando há necessidade de resolver assuntos que envolvam o patrimônio, tal quando as partes exigem um profissional capacitado para área em questão. O quesito mais destacado foi a nomeação para substituição de perito suspeito ou impedido. 
Quanto à escolha do perito, o resultado demonstra que a maioria dos magistrados escolhem por meio do Banco de dados do Fórum e que, às vezes, designa um perito do seu banco de dados particular. Aponta que quase nunca a escolha é feita por indicação de outro juiz, assim como pelo banco de dados do Conselho Federal de Contabilidade, que dentre todos, é o menos utilizado. Há também quem use o banco de dados do CAJU - Cadastro de Auxiliares da Justiça.

Pela pesquisa pode constatar que todas as características, como linguagem clara e acessível, respostas aos requisitos, fundamentação e confiabilidade, apresentaram a demanda "satisfatório" e apresentou uma média respondida por magistrados de 4/1 e 3/2, a padronização conforme a norma sobressaiu com média 5 tendo em vista que todos os magistrados responderam satisfatório para este requisito.

Neste ponto, o questionamento apontou que os laudos periciais contábeis auxiliam os questionados à tomada de decisão, permitindo convicção necessária para julgar. Nota-se na figura 3 que $80 \%$ opinaram nos 2 tópicos mais positivos do questionário, enquanto não houve nenhum para nunca, comprovando a assistência do laudo.

Figura 3: Os laudos periciais contábeis te auxiliam na decisão da sentença?

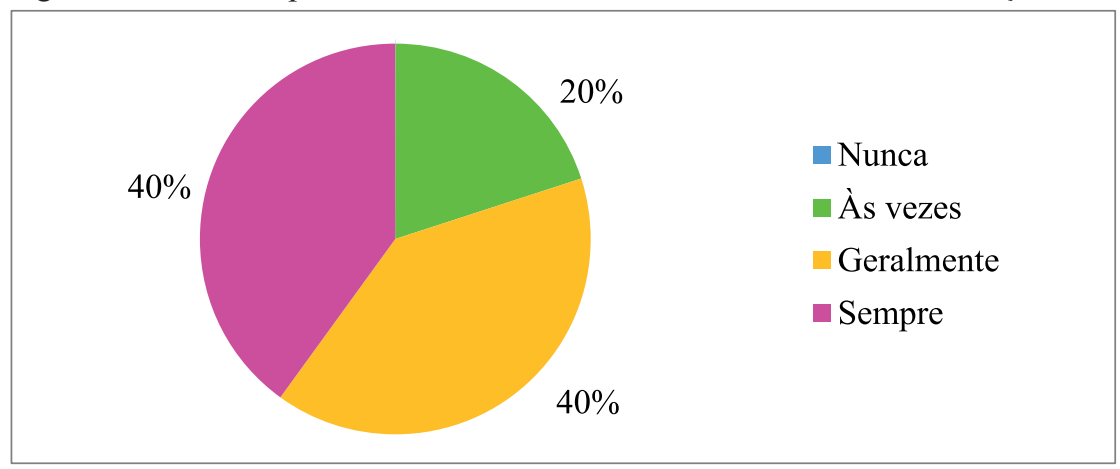

Fonte: Elaborado pelas autoras, 2017.

A principal pergunta efetuada neste questionário apontou que os laudos atendem "geralmente" com uma perspectiva de $80 \%$, conforme figura 4 . Sendo assim, o laudo ficou com a segunda melhor nota, porém necessitando que haja aperfeiçoamento, conforme julgamento de $20 \%$, expondo que, às vezes, atendam à expectativa de magistrado. 
Figura 4: Os laudos atendem sua expectativa?

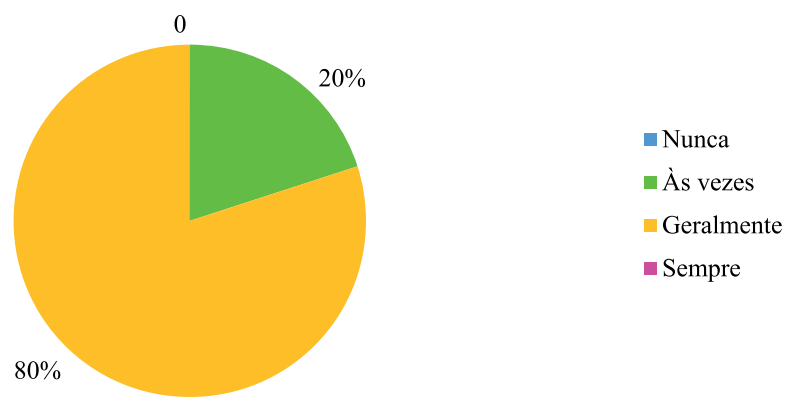

Fonte: Dados da pesquisa, 2017.

A pesquisa apresentou que as características de "linguagem simples", "linguagem coerente", "objetividade sobre o assunto" e a "estrutura do laudo" gozaram de um índice positivo próximo aos 100\%, conforme figura 5. Então, todas são importantes para a composição do laudo pericial e não podem ficar afastadas da prática do profissional contábil.

Figura 5: Quais características são imprescindíveis nos laudos periciais contábeis?

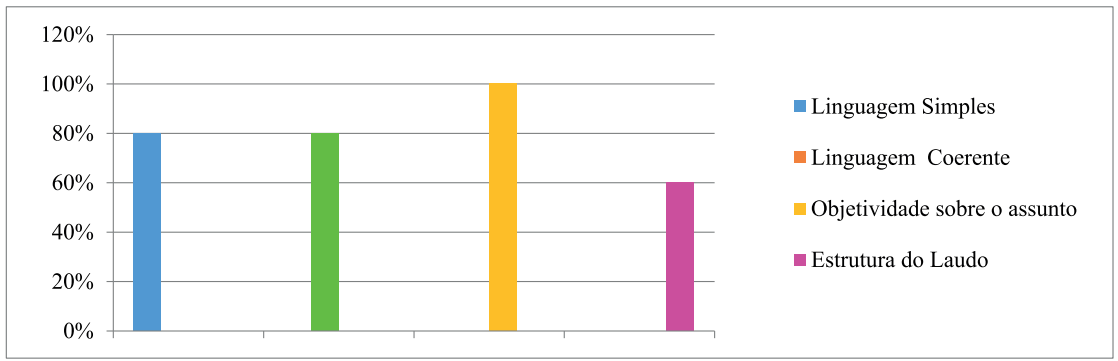

Fonte: Elaborado pelas autoras

\section{CONSIDERAÇÕES FINAIS}

O recente estudo buscou mensurar a qualidade e relevância do laudo pericial contábil por meio do ponto de vista dos juízes do município de Umuarama e região.

Com os resultados auferidos, é notável a euforia da lide em relação ao laudo contábil, determinando que o trabalho realizado pelo contador é de fato um objeto de ajuda para o julgador. 
Observa-se que há mais magistrados no gênero masculino, na região de Umuarama, do que feminino, mas que com o tempo estão buscando paridade profissional. Além do mais, repara-se que a maioria atua na área há mais de uma década e são graduados em direito, mas também em Ciências Contábeis.

As caraterísticas mais aguardadas pelos juízes em relação aos peritos contadores, são as que englobam a índole do profissional, assim como zelo e ética, sem se ausentar de buscar conhecimento técnico e ter comportamento profissional.

Referente à nomeação do perito, a principal situação para a solicitação é para substituir um profissional que se encontra suspeito ou impedido para trabalhar no caso, como menciona a lei.

A maneira mais utilizada para escolher o perito contador é por meio do banco de dados do Fórum. Portanto, há de se ressaltar que o site do CRC-PR possui banco de dados de peritos contadores e que esta profissão só deverá ser exercida por estes profissionais, mediante aprovação no exame de qualificação técnica, se destacando além do banco de dados específico de contadores - CFC - sendo o menos utilizado pelo julgador. Nesse banco de dados só estará os aprovados no exame de qualificação técnica, conforme NBC PP 02, a qual aufere os conhecimentos e a competência profissional dos contadores que atuam na área de perícia contábil.

Compreende-se que os julgadores consideraram que não houve carência na estrutura do laudo, pois existe uma uniformização em conformidade com a norma NBC TA 700.

Também percebeu-se pelos resultados da pesquisa que os laudos periciais contábeis auxiliam os magistrados na maioria das vezes em suas tomadas de decisões. Para os juízes, o ofício do perito contador está sendo desempenhado com qualidade e conhecimento.

Finalizando, o presente estudo informa a satisfação dos magistrados com os laudos periciais contábeis, sendo estes relevantes e importantes para os que usufruem desse objeto para as tomadas de decisões na magistratura.

\section{REFERÊNCIAS}

ALBERTO, V. L. P.; Perícia contábil. 3. ed. São Paulo: Atlas, 2002.

AlBerto FILHO, R. P.; Da Perícia ao Perito. 3. ed. Niterói: Impetus, 2011.

BLEIL, C.; SANTIN, L. A. B. A perícia contábil e sua importância sob o olhar dos magistrados. Revista de administração e ciências contábeis do IDEAU, v. 3, n. 7, 2008. Disponível em: <http://www.spell.org.br/documentos/ 
ver/44002/a-qualidade-dos-laudos-periciais-contabeis--um-estudo-de-casomultiplo-no-estado-do-amazonas>. Acesso em: 06 jun 2017.

BORGES, L. O.; ALVES FILHO, A. A mensuração da motivação e do significado do trabalho. Estudos de psicologia, p. 177-194, 2001. Disponível em: <http://www.scielo.br/pdf/epsic/v6n2/7272.pdf>. Acesso em: 25 maio 2017.

BRASIL. Lei n $\mathbf{1 3 . 1 0 5}$ de 16 de março de 2015 do Código de Processo Civil. Disponível em: <http://www.planalto.gov.br/ccivil_03/_ato2015-2018/2015/lei/ 113105.htm>. Disponível em: 19 maio 2017.

CARVAlHO, E. B.; MARQUES, C. Perícia Contábil nas relações de trabalho em processos judiciais. Reflexão contábil, vol. 24, n. 2, jul-dez/2005.

Disponível em: $<$ http://www.spell.org.br/documentos/ver/41825/periciacontabil-nas-relacoes-de-trabalho-em-processos-judiciais $>$. Acesso em: 10 jun 2017.

CFC-CONSELHO FEDERAL DE CONTABILIDADE. Publicação D.O.U, 25 de março de 2014. Dispões sobre a NBC PG 100 - Aplicação Geral aos Profissionais da Contabilidade. Disponível em: <www.cfc.org.br/sisweb/SRE/ docs/NBCPG100.doc $>$. Acesso em: 19 maio 2017.

\section{CFC-CONSELHO FEDERAL DE CONTABILIDADE. Resolução CFC}

$\mathbf{n}^{\mathbf{0}} \mathbf{8 0 3}, 10$ de outubro de 1996. Aprova o Código de Ética Profissional do Contador - CEPC. Disponível em: <http://www1.cfc.org.br/sisweb/SRE/docs/ RES_803.pdf $>$. Acesso em: 29 maio 2017.

\section{CFC-CONSELHO FEDERAL DE CONTABILIDADE. Resolução CFC n ${ }^{0}$}

1231, 27 de novembro de 2009. Aprova a NBC TA 700 - Formação da Opinião e Emissão do Relatório do Auditor Independente sobre as Demonstrações Contábeis. Disponível em:<http://portalcfc.org.br/wordpress/wpcontent/ uploads/2013/01/NBC_TA_AUDITORIA.pdf $>$. Acesso em: 08 nov 2017

CFC-CONSELHO FEDERAL DE CONTABILIDADE. Resolução CFC n ${ }^{0}$ 1243, 10 de dezembro de 2009a. Aprova a NBC TP 01 - Perícia Contábil. Disponível em: <http://cfc.org.br/wp-content/uploads/2016/02/NBC_TP_01. pdf $>$. Acesso em: 14 maio 2017.

1244, 10 de dezembro de 2009b. Aprova a NBC PP 01 - Perícia Contábil. 
Disponível em: <http://cfc.org.br/wp-content/uploads/2016/02/NBC_PP_01. pdf $>$. Acesso em: 14 maio 2017.

CFC-CONSELHO FEDERAL DE CONTABILIDADE. Resolução CFC no 1502, 21 de outubro de 2016 Aprova a NBC PP 02 - Exame de Qualificação Técnica para Perito Contábil. Disponível em: $<$ http://cfc.org.br/tecnica/normasbrasileiras-de-contabilidade/nbc-pp-do-perito-contabil/>. Acesso em: 19 maio 2017.

CÓDIGO DE ÉTICA DA MAGISTRATURA. Disponível em: <http://www.cnj. jus.br/publicacoes/codigo-de-etica-da-magistratura>. Acesso em: 17 maio 2017.

CRESWELL, J. W.; et al. Qualitative research designs: selection and implementation. The Counseling Psychologist. Miami, v. 35, n. 2, p. 236-264, 2007. Disponível em: <http://journals.sagepub.com/ doi/10.1177/0011000006287390 > . Acesso em: 19 ago 2017

CRUZ, W. C. Perícia contábil \& lides fiscais municipais. Curitiba: Juruá, 2008 .

CRUZ, A. P.; XAVIER, R. F.; SANTOS, L. B. A; CARMO, M. A qualidade dos laudos periciais contábeis: um estudo de caso múltiplo no estado do Amazonas. Caderno profissional de administração. Unimep, v. 6, n. 2, 2016. Disponível em: <http://www.spell.org.br/documentos/ver/44002/a-qualidade-dos-laudospericiais-contabeis--um-estudo-de-caso-multiplo-no-estado-do-amazonas >. Acesso em: 23 maio 2017.

GIL, A. C. Como elaborar projetos de pesquisa. 4. ed.São Paulo: Editora Atlas S.A, 2009.

GONÇALVES, P. C.; MACHADO, M. R. R.; MACHADO, L. S.; ZANOLLA, E. Características do perito-contador: perspectiva segundo juízes da Justiça Federal, advogados da União e peritos-contadores no contexto goiano. Revista Contemporânea da Contabilidade. UFSC, Florianópolis, v. 11, n. 2, p. 119-140, jan/abr. 2014. Disponível em: <https://periodicos.ufsc.br/index.php/ contabilidade/article/view/21758069.2014v11n22p119/26478>. Acesso em: 10 jun 2017.

HOOG, W. A. Z. Tricotomia contábil \& Sociedades empresariais. Curitiba: Juruá, 2006. 
HOOG, W. A. Z.; PETRENCO, S. A. Prova pericial contábil. Curitiba: Juruá, 2003.

HINTEMANN, L. H. Um estudo da aplicação da teoria da expectativa e da teoria da ancoragem na motivação para desempenho de alunos no ensino médio. 2006. 67 f. Dissertação (mestrado) - Universidade Federal do Rio Grande do Norte, 2000. Disponível em: $<$ https://repositorio.ufrn.br/jspui/ bitstream/123456789/15103/1/LuizHH.pdf>. Acesso em: 25 maio 2017.

LEITÃO JUNIOR, L. R. D. J.; SLOMSKI, V. G.; MENDONÇA, J. F.; PELEIAS, I. R. A informação contábil no âmbito da magistratura: a percepção de juízes sobre o papel do laudo pericial no processo de tomada de decisão judicial. Disponível em: $<$ http://www.congressousp.fipecafi.org/ anais/artigos102010/149.pdf $>$. Acesso em: 19 maio 2017.

MAGAlHÃeS, A. D. F.; SOUZA, C.; FAVERO, H. L. Perícia contábil. 4. ed. São Paulo: Atlas, 2004.

MARCONI, M. A.; LAKATOS, E. M. Fundamentos de metodologia científica. 6. ed. São Paulo: Atlas S.A., 2009.

MEDEIROS, T. A.; NEVES JUNIOR, I. J. A qualidade do laudo pericial elaborado pelo perito contador na visão de magistrados do Rio de Janeiro e Brasília. RCB: Revista Brasileira de Contabilidade, Brasília: Conselho Federal de Contabilidade, v. 35, nº 159 (maio./jun.2006), p.45-57 disponível em: $<$ http://rbc.cfc.org.br/index.php/rbc/article/view/757/495>. Acesso em 06 jun 2017.

MORAIS, A. C.; FRANÇA, J. A. Perícia judicial e extrajudicial: uma abordagem conceitual e prática, 2. ed. Brasília: Qualidade Brasília,2004.

MULLER, A. N.; ANTONIK, L. R.; FERREIRA JUNIOR, V. Cálculos periciais. Curitiba: Juruá, 2008.

NEVES JUNIOR, I. J.; CERQUEIRA, J. G. M.; GOTTARDO, M. S. P; BARRETO, M. D.; Perícia Contábil Judicial: A Relevância e a Qualidade do Laudo Pericial Contábil na Visão dos Magistrados do Estado do Rio de Janeiro. Pensar contábil. Rio de Janeiro, v. 16, n. 59, p. 49-57, jan/abr. 2014. Disponível em: <http://www.spell.org.br/documentos/ver/31237/periciacontabil-judicial--a-relevancia-e-a-qualidade-do-laudo-pericial-contabil-navisao-dos-magistrados-do-estado-do-rio-de-janeiro>. Acesso em: 03 jun 2017. 
NEVES JUNIOR, I. J.; MOREIRA, S. A.; RIBEIRO, E. B. Perícia Contábil: estudo da percepção dos juízes de Primeira Instância do Trabalho sobre a qualidade e relevância do trabalho do perito. Revista brasileira de gestão de negócios. São Paulo, v. 15, n. 47, p. 300-320, abr/jun. 2013. Disponível em: $<$ https://rbgn.fecap.br/RBGN/article/viewFile/1254/956> Acesso em: 11 abr 2017.

NEVES JUNIOR, I. J; RIVAS, I. I. V. A qualidade do laudo pericial contábil e sua influência na decisão de magistrados nas comarcas localizadas no Distrito Federal e na cidade de Fortaleza. Encontro da ANPAD, XXXI, 2007, Rio de Janeiro. Disponível em: <http://www.anpad.org.br/admin/pdf/CON-A3240. pdf $>$. Acesso em: 10 jun 2017.

OLIVEIRA, S. L.; Tratado de metodologia científica. 2. ed. São Paulo: Pioneira, 1998.

ORNELAS, M. M. G.; Perícia contábil. 5. ed. São Paulo: Atlas, 2003.

PASSOS, D. V. S.; Concurso público e transformações no judiciário brasileiro: os modelos de seleção e as novas competências para o exercício da magistratura. Dissertação, Ceará, 2013. Disponível em: <https://uolp.unifor.br/ oul/conteudosite/F1066348634/Dissertacao.pdf>. Acesso em: 03 jun 2017.

PIRES, M. A. A. A perícia contábil, reflexões sobre seu verdadeiro significado e importância. Contabilidade Vista \& Rev. Belo Horizonte, v.10, $n^{\circ} 1$, p.1827, mar. 1999. Disponível em: < http://www.fumec.br/revistas/facesp/article/ view/3>. Acesso em: 10 jun 2017.

PRUNES, J. L. F. A prova pericial no processo trabalhista. 2. ed. São Paulo: Ed. LTr, 1995.

RICHARDSON, R. J. Pesquisa social: métodos e técnicas. 3. ed. São Paulo: Atlas, 1999.

ROBBINS, S.P. Comportamento organizacional. São Paulo: Pearson Education, 2002.

SÁ, A. L. Fundamentos da contabilidade geral. 2. ed. Curitiba: Juruá, 2008.

SÁ, A. L. Perícia contábil. 5. ed. São Paulo: Atlas, 2002. 
SANTANA, C. M. S. A perícia contábil e sua contribuição na sentença judicial: um estudo exploratório. Dissertação, USP, São Paulo, 1999. Disponível em: <http://www.teses.usp.br/teses/disponiveis/12/12136/tde06102004-161123/pt-br.php>. Acesso em: 25 maio 2017.

VROOM, V. H.; Work and motivation. New York: John Wiley, 1964.

ZOCHIO, M. Qualidade dos laudos periciais emitidos na comarca de São Paulo. Dissertação, 2010, São Paulo. USP-Universidade de São Paulo. Disponível em: <http://www.teses.usp.br/teses/disponiveis/3/3142/tde18082010-164616/pt-br.php>. Acesso em: 06 jun 2017.

ZOLET, K.; SILVÉRIO, A. C. A qualidade do laudo pericial contábil e sua influência na decisão Judicial. Monografia. In UTFPR-Universidade Tecnológica Federal do Paraná - Campus Pato Branco. Disponível em: $<$ http:// revistas.utfpr.edu.br/pb/index.php/ecap/article/view/781/4291>. Acesso em 06 jun 2017 